\title{
Nonoptimality of the Friedman Rule with Capital Income Taxation
}

\author{
Alberto Petrucci* $\quad$ LUISS University \\ October 2008
}

\begin{abstract}
This paper studies the efficient taxation of money and factor income in intertemporal optimizing growth models with infinite horizons, transaction costs technologies and flexible prices. Second-best optimality calls for a positive inflation tax and a non-zero capital income tax when there are restrictions on taxation of production factors or profits/rents. Our cases of nonoptimality of the Friedman rule -which differ from those of Mulligan and Sala-i-Martin (1997) and extend substantially those of Schmitt-Grohè and Uribe (2004a)- follow from the violation of the Diamond and Mirrlees (1971) principle on production efficiency.
\end{abstract}

Keywords: Optimal inflation tax; Factor taxation; Transaction costs technology; Second-best analysis; Capital accumulation.

JEL classification: E31, E52, E61, E63, O41.

*This paper was written when I was visiting Nuffield College, Oxford University. I would like to thank Steve Nickell for the hospitality. Moreover, I am grateful to Ned Phelps and Michael Woodford for fruitful discussions, and to Pierpaolo Benigno for constructive comments. Address: LUISS University, Department of Economics, Viale Romania 32, 00197, Rome, Italy. Tel. +39 068522 5737; Fax +39 068522 5949; E-mail: albpetru@luiss.it. 


\section{Introduction}

Should money be exempted from taxation? Initially, two contrasting answers were given to this question. One was provided by Friedman (1969), who claimed, from a normative standpoint, that the inflation tax -the nominal interest rate- should be brought to zero, when lump-sum taxes are available. Money should be tax free because the marginal private cost of holding money (that is, the nominal interest rate) should be equated to the marginal social cost of money, which is zero as money is costless to produce. The Friedman rule is a first-best monetary policy prescription obtained in a partial equilibrium setup. ${ }^{1}$

A second answer was given, in a different direction, by Phelps (1973). On the basis of the Ramsey (1927) optimal differential-tax analysis, Phelps argued that, when lump-sum taxes are not available and a prescribed amount of revenue has to be raised by using distortionary taxes, it is socially optimal to tax money - that is, to set a positive nominal interest rate - in addition to all other goods.

Economics scholars have widely studied the issue of the optimal inflation tax, since the appearance of the Friedman (1969) and Phelps (1973) seminal contributions. See Woodford (1990) and Kocherlakota (2005) for comparative analyses of the state of knowledge in different moments.

Some recent articles, based on dynamic general equilibrium analysis, show that the optimality of the Friedman rule is a general result, since it is also satisfied in a second-best world when distortionary income or consumption taxes are used to finance an exogenous flow of government spending. This is demonstrated in intertemporal optimizing models with infinite-lived agents, endogenous labor-leisure choices and flexible prices, for example, by Kimbrough (1986), Faig (1988), Guidotti and Vegh (1993), Chari, Christiano and Kehoe (1996), Correia and Teles $(1996,1999)$, and De Fiore and Teles (2003).

Kimbrough (1986) obtains that the optimal monetary policy is the Fried-

\footnotetext{
${ }^{1}$ It must be acknowledged that considerations on the inefficiency of a positive inflation tax have been made ante litteram by Bailey (1956) and, through the development of a formal model, Samuelson (1968).
} 
man rule when the shopping-time technology is constant returns to scale. Correia and Teles (1996) generalize the zero inflation tax result to any homogeneous transaction costs technology. Chari, Christiano and Kehoe (1996) show that such a policy rule holds in three monetary models - the cash-inadvance model based on the distinction between cash goods and credit goods, the money in the utility function model and the shopping-time cost model - when conditions on separability and homotheticity of preferences are satisfied. Also Correia and Teles (1999) confirm Friedman's (1969) result when money enters the utility function. De Fiore and Teles (2003) demonstrate that the validity of the Friedman policy scheme does not depend on the choice of the alternative tax instruments that are used to obtain a given amount of revenue, if the transactions technology -homogeneous of any degree- incorporates the plausible assumption that money is unit elastic with respect to the price level gross of consumption taxes.

Chamley (1985), Faig (1988), Woodford (1990) and Guidotti and Vegh (1993), instead, discuss some theoretical cases in which the zero seignorage result is nonoptimal. In a representative agent model of capital formation, Chamley (1985) argues that the optimal dynamic tax configuration is one in which money and labor taxes should finance government expenditure. Woodford (1990) underlines the fact that if consumption and money are gross substitutes, the optimal inflation tax is different from zero. Guidotti and Vegh (1993) show that the optimal inflation tax is zero under income taxation, but may be positive under consumption taxation, when the shopping-time cost function is constant returns to scale; if, instead, the transaction technology is not constant returns to scale, the Friedman rule is invalid under either consumption or income taxation.

Two justifications have been provided for the optimality of the zero inflation tax in a world with distortionary taxes. One is based on the classic principle of public finance on production efficiency established by Diamond and Mirrlees (1971). According to this principle, when the production function is constant returns to scale, intermediate goods should be exempted from taxation as taxes are levied only on final goods. As money is an intermediate input in economies with a transaction technology, the optimal inflation tax 
has to be zero to preserve production efficiency. ${ }^{2}$ If money enters the utility function $\grave{a}$ la Sidrauski and preferences are homothetic in money and consumption as well as separable in leisure, the Friedman "full liquidity" rule is satisfied because such an economy is equivalent to one with a transactions technology. ${ }^{3}$ When the cash-credit goods model, developed by Lucas and Stokey (1983), is considered, the Friedman rule derives from the Atkinson and Stiglitz (1972) principle of uniform taxation of all types of consumption goods (which follows from the intermediate goods result). In this case, a zero inflation tax ensures the optimal tax treatment of cash goods relative to credit goods.

A second justification, alternative to the first one, follows from the assumption that money is a free good. Also in a second-best world (like in the first-best case considered by Friedman, 1969), it is the zero marginal cost of producing money that implies a zero opportunity cost of holding money, i.e. zero inflation tax, to guarantee efficiency. Correia and Teles (1996, 1999), and De Fiore and Teles (2003) show that the Friedman rule is nonoptimal when money is no longer a free primary input (that is, the production of money requires labor as an input).

The zero inflation tax result is criticized on a systematic basis by Mulligan and Sala-i-Martin (1997), who make a comparative investigation of the scattered results of the literature based on infinite horizons and flexible prices by using a unified framework that embodies previous models and results as particular cases. They show that the optimality of the Friedman rule is fragile as its validity, far from being general, strictly depends on the assumptions adopted on the utility functions and/or the shopping-time technology; these assumptions concern, for example, the absence of the scale elasticity in the money demand and the fact that some taxes could be paid or not by using money.

\footnotetext{
${ }^{2}$ See, for example, Kimbrough (1986), Guidotti and Vegh (1993), Chari, Christiano and Kehoe (1996), and Chari and Kehoe (1999).

${ }^{3}$ See Chari, Christiano and Kehoe (1996), and, for the generalization of such a result, Correia and Teles (1999). However, if the preference conditions were not satisfied, the equivalence (in terms of the optimal inflation tax analysis) of the money in the utility function model with the shopping-time one would be questionable (see Mulligan and Salai-Martin, 1997).
} 
Schmitt-Grohè and Uribe (2004a) find that the consideration of firms with market power may invalidate the optimality of the zero seignorage result in a stochastic model with pecuniary shopping-costs and no capital; in particular, they show that the Friedman rule is invalid if dividends, which exert only income effects, cannot be taxed at the optimal $100 \%$ rate.

The implications of other environmental conditions for the Friedman monetary policy -like, for example, OLG demographics, agent heterogeneity, and price rigidity- have been studied, among many others, by Abel (1987), Gahvari (1988), Schmitt-Grohè and Uribe (2004b), Bhattacharya, Haslag and Martin (2005), Lagos and Wright (2005), and Correia, Nicolini and Teles (2008). ${ }^{4}$

In this paper, we investigate the question of the optimal inflation tax through infinitely-lived models of capital formation with flexible prices and distortionary capital and labor income taxes. ${ }^{5}$ In order to avoid that the paper results might depend on the properties of preferences or technologies for producing transaction services (whose role has been discussed in details by Mulligan and Sala-i-Martin, 1997), a shopping-time model with a homogeneous transaction cost technology (that generally supports the Friedman rule in standard setups) is employed purposefully.

We characterize cases, new in the literature, in which it is optimal to tax money in addition to factors of production in order to finance a fixed stream of public spending. The Phelps (1973) prescription on the secondbest monetary policy is valid when there are restrictions on taxation; that is, when there are factors of production, monopoly profits or rents that cannot be taxed optimally. We show that in general the hypotheses that violate

\footnotetext{
${ }^{4}$ See Kocherlakota (2005) for a selective review of the recent literature highlighting the role of such contexts.

${ }^{5}$ To the best of my knowledge, the role of the capital stock for the optimal taxation of money has only been studied by Chamley (1985), who, however, did not consider capital taxation. In the literature on the Friedman rule, the inflation tax is always considered together with consumption and/or labor income taxes. In models in which labor is the unique factor of production and there are infinite horizons, consumption taxation and labor taxation are de facto equivalent. This correspondence does not hold when consumption taxes are paid with money (that is, consumption expenditure, instead of consumption, enters the transaction technology) as supposed, for example, by Kimbrough (1986) and Guidotti and Vegh (1993); see Mulligan and Sala-i-Martin (1997).
} 
the Friedman rule also lead to the nonoptimality of the Judd (1985) and Chamley (1986) result on the zero capital income taxation.

In economies in which firms have market power or there are decreasing returns to scale in the reproducible factors, for example, the optimality of the zero inflation tax is valid if either capital and profits/rents are taxed at the same optimally chosen rate or profits/rents are taxed at the $100 \%$ rate. If profits are taxed less than capital income, the normative analysis suggests that collecting some revenue from seignorage is optimal. These findings generalize and extend the result of Schmitt-Grohè and Uribe (2004a), who instead show that the Friedman rule is satisfied only if fiscal confiscation of monopoly profits is permitted.

Limitations on tax setting imply that the social planner has to take into account further constraints (in addition to the implementability and feasibility constraints) when choosing the Ramsey allocation. This fact results in an optimal inflation tax that is different from zero.

In models in which the marginal cost of producing money is zero, we obtain that the optimality of the Friedman rule is denied because the Diamond and Mirrlees (1971) principle of tax exemption of intermediate goods -that also supports the zero capital income tax result- is violated. ${ }^{6}$ This observation is consistent with Stiglitz and Dasgupta (1971), and Munk (1980), who argue that production efficiency is undermined by the existence of profits or the impossibility of setting taxation at an optimal level for some goods.

Finally, as a particular case, we show that the consideration of exogenous government transfers received by consumers, in an intertemporal optimizing growth model with infinite horizons, results in a positive optimal inflation tax and a zero optimal capital income tax. This result stems from the fact that government transfers have to be expressed in terms of consumption relative prices (and hence multiplied by a function of real money balances) when included in the implementability constraint.

The paper is structured as follows. Section 2 investigates the optimal monetary policy in a perfectly competitive economy when it is not possible to

\footnotetext{
${ }^{6}$ In the normative analysis of dynamic capital taxation, the role of restrictions on the set of the available tax instruments is studied by Jones, Manuelli and Rossi $(1993,1997)$, and Correia (1996).
} 
tax some inputs. Section 3 presents a monetary model with monopolistically competitive firms and analyzes the normative properties of money and factor income taxation. Section 4 examines the case of profits/rents in a competitive economy with non-reproducible inputs. In Section 5, the implications of fixed government transfers for the inflation tax are discussed. Section 6 concludes.

\section{Perfect competition and tax restrictions}

\subsection{The model}

Consider a monetary economy, defined in continuous time, in which there are infinite-lived consumers and perfectly competitive firms. In this economy, output is produced by using physical capital $k$, labor $l$, and a third factor of production $z$, that cannot be taxed or subsidized. ${ }^{7}$ The supply of $z$ is elastic.

The production technology is given by $y=F(k, l, z)$, which is regular in a neoclassical sense and linearly homogeneous in the three inputs. Maximum profit requires that factors of production are paid their marginal products; that is,

$$
\begin{aligned}
& F_{k}(k, l, z)=r, \\
& F_{l}(k, l, z)=w, \\
& F_{z}(k, l, z)=v,
\end{aligned}
$$

where $r$ is the real rental on capital, $w$ the real wage and $v$ the price (in real terms) of $z$.

Consumers, whose number remains constant over time, maximize the integral utility

\footnotetext{
${ }^{7}$ We do not give a precise interpretation to $z$ and leave it undefined so that different particular cases can be considered.
} 


$$
\int_{0}^{\infty} U(c, x, s) \mathrm{e}^{-\rho t} d t
$$

where $c$ is consumption, $x$ leisure, $s=\bar{z}-z, \bar{z}$ the exogenous endowment of $z$ and $\rho$ the fixed rate of time preference. The instantaneous utility function $U(\cdot)$ is strictly increasing and concave in its arguments. $c, x$ and $s$ are assumed to be normal goods.

Transactions required for consumption need time. Money balances facilitate transactions by reducing the amount of shopping time $e$. The amount of time employed in transactions is described by the technology

$$
e=T(c, m)=c^{h} q\left(\frac{m}{c}\right)
$$

where $m=\frac{M}{p}$ denotes real money balances, $M$ the nominal money stock and $p$ the output price. $T(\cdot)$, which is homogeneous of degree $h>0$ in $c$ and $m$, satisfies the properties: $T_{c}>0, T_{m} \leqslant 0, T_{c c}>0, T_{m m}>0$ and $T_{c m}<0 .{ }^{8}$ The function $q\left(\frac{m}{c}\right)=\frac{e}{c^{h}}$ has the properties: $q^{\prime} \leqslant 0$ and $q^{\prime \prime}>0$. When $T_{m}=q^{\prime}=0$, the money-consumption ratio is constant and equal to $\gamma^{*}=\left(\frac{c}{m}\right)^{*}$, which corresponds to the satiation level of real money balances. ${ }^{9}$

The fixed time endowment, normalized to one, is used for consuming leisure, working and making transactions; that is,

$$
1=x+l+e .
$$

${ }^{8}$ While $T_{c c}>0$ and $T_{m m}>0$ guarantee the convexity of the transactions cost technology and the fact that the use of money has diminishing returns, $T_{c m}<0$, instead, ensures a positive scale elasticity (i.e., a positive effect of consumption on the demand for money). $T_{c m}<0$ follows from the signs of the other partial derivatives of $T(\cdot)$. In fact, by using the homogeneity of degree $h$ of $T(\cdot)$, it can be easily verified that $T_{c m}=-\frac{\left[(1-h) T_{m}+m T_{m m}\right]}{c}=-\frac{\left[(1-h) T_{c}+c T_{c c}\right]}{m}<0$.

${ }^{9}$ A plausible functional form for $q(\cdot)$ is given by $q\left(\frac{m}{c}\right)=Q \frac{m}{c}\left(\frac{c}{m}-\gamma^{*}\right)^{2}$, where $Q$ is a positive constant. This functional form comes from Mulligan and Sala-i-Martin (1997) when the homogeneity of degree zero of $q(\cdot)$ is imposed. If $h=\gamma^{*}=0$, the Baumol-Tobin inventory model is obtained. 
Consumers accumulate wealth by holding capital, money and government bonds $b$, which are perfectly substitutable with capital. The intertemporal budget constraint of consumers - obtained by integrating their flow budget constraint forward and incorporating the condition precluding Ponzi games - is described by

$$
\int_{0}^{\infty}\left[c+i m-\left(1-\tau_{l}\right) w l-v z\right] \mathrm{e}^{-\int_{0}^{t}\left(1-\tau_{k}\right) r d u} d t=k_{0}+a_{0},
$$

where $i=\left(1-\tau_{k}\right) r+\pi$ represents the nominal interest rate, i.e. the after-tax real interest rate plus the inflation rate $\pi, \tau_{l}$ the ad valorem labor income tax rate, $\tau_{k}$ the ad valorem capital income tax rate, $k_{0}+a_{0}$ nonhuman wealth a time 0 , and $a_{0}=b_{0}+m_{0}$ (where $b_{0}$ and $m_{0}$ are the stock of goverment bonds and money balances in real terms at time 0 , respectively). $a_{0}$ is set equal to zero without any loss of generality. The hypothesis that $z$ is untaxed/unsubsidized has been considered in (5).

The maximization of (2) subject to (3), (4) and (5) yields the following first-order conditions ${ }^{10}$

$$
\begin{gathered}
U_{c} \mathrm{e}^{-\rho t}=\left[1+\left(1-\tau_{l}\right) w T_{c}\right] \lambda \mathrm{e}^{-\int_{0}^{t}\left(1-\tau_{k}\right) r d u}, \\
U_{x} \mathrm{e}^{-\rho t}=\left(1-\tau_{l}\right) w \lambda \mathrm{e}^{-\int_{0}^{t}\left(1-\tau_{k}\right) r d u}, \\
U_{s} \mathrm{e}^{-\rho t}=v \lambda \mathrm{e}^{-\int_{0}^{t}\left(1-\tau_{k}\right) r d u} \\
-\left(1-\tau_{l}\right) w T_{m}=i
\end{gathered}
$$

\footnotetext{
${ }^{10}$ The way in which the solution of this optimal dynamic problem is specified follows, mutatis mutandis, from Lucas (1990). Such a specification is preparatory for the normative analysis of taxation, based on the Lucas and Stokey (1983) methodology, developed below.
} 
where $\lambda=U_{c}[c(0), x(0)]=U_{c}[0]$ is the Lagrange multiplier on the intertemporal budget constraint (5) at time 0 . From equation (6a), the Euler equation for the "Keynes-Ramsey rule" is obtained

$$
\rho-\frac{d}{d t} \ln \left\{\frac{U_{c}}{\left[1+\left(1-\tau_{l}\right) w T_{c}\right]}\right\}=\left(1-\tau_{k}\right) r
$$

Equation (6b), which can be written, after using (6a), as $\frac{U_{x}}{U_{c}}=\frac{\left(1-\tau_{l}\right) w}{\left[1+\left(1-\tau_{l}\right) w T_{c}\right]}$, asserts that the marginal rate of substitution of consumption for leisure must equal the opportunity cost of leisure in terms of consumption; this opportunity cost is equal to the after-tax wage divided by the price of consumption, i.e., one plus the marginal-time cost of consumption (measured in terms of the take-home wage). A similar efficiency condition is obtained by combining (6c) and (6a); that is, $\frac{U_{s}}{U_{c}}=\frac{v}{\left[1+\left(1-\tau_{l}\right) w T_{c}\right]}$. Equation (6d) describes the demand for real money balances in implicit terms. Equation (6e) ensures that, in the intertemporal equilibrium, the rate of return on consumption -i.e., the LHS- is equal to the after-tax return on nonhuman wealth, namely, the after-tax real interest rate.

The resource constraint states that output is equal to aggregate demand:

$$
F(k, l, z)=c+\dot{k}+g
$$

The government finances the budget deficit by issuing public debt and money. The government budget constraint is given by

$$
\dot{b}+\dot{m}=\left(1-\tau_{k}\right) r(b+m)+g-\left(\tau_{k} r k+\tau_{l} w l+i m\right) .
$$

\subsection{Optimal policy analysis}

The problem of the efficient tax policy, known as the 'Ramsey problem', prescribes that the utility of the representative consumer is maximized by 
taking into account the competitive equilibrium with distortionary taxes and the constraint that a given amount of revenue has to be raised.

We study the Ramsey problem by using the 'primal method' to optimal taxation in the version developed by Lucas and Stokey (1983). This method employs the implementability constraint, obtained from the households' intertemporal budget constraint by expressing prices and taxes in terms of quantities through the marginal efficiency conditions of consumers (6).

Plugging the following relationships

$$
\begin{gathered}
\left(1-\tau_{l}\right) w=\frac{U_{x} \mathrm{e}^{-\rho t}}{\lambda \mathrm{e}^{-\int_{0}^{t}\left(1-\tau_{k}\right) r d u}}=\frac{U_{x}}{\left(U_{c}-U_{x} T_{c}\right)} \text { and } \\
v=\frac{U_{s} \mathrm{e}^{-\rho t}}{\lambda \mathrm{e}^{-\int_{0}^{t}\left(1-\tau_{k}\right) r d u}}=\frac{U_{s}}{\left(U_{c}-U_{x} T_{c}\right)}
\end{gathered}
$$

-obtained by combining (6a), (6b) and (6c)- and $\lambda=U_{c}[0]$ into (5), one obtains, after using the property of homogeneity of degree $h$ of $T(\cdot)$ and rearranging, the implementability constraint; that is,

$$
\int_{0}^{\infty}\left\{c U_{c}-U_{x}[1-x-(1-h) T]-z U_{s}\right\} \mathrm{e}^{-\rho t} d t=\lambda k_{0}
$$

As it is not possible to tax $z$, the complete characterization of the Ramsey problem has to take into account the private efficiency conditions (from both the consumer and firm standpoints) for factor $z$-otherwise the competitive equilibrium cannot be decentralized. Such a condition is given by $\frac{U_{s}}{\left(U_{c}-U_{x} T_{c}\right)}=F_{z}$, obtained from (1c), (6a), (6b) and (6c).

Define the pseudo-welfare function of the social planner as

$$
W(c, x, z, m, k, \Phi)=U(c, x, \bar{z}-z)+\Phi\left\{c U_{c}-U_{x}[1-x-(1-h) T]-z U_{s}\right\},
$$

where $\Phi$ is the Lagrange multiplier associated with $(7)$ and $T=T(c, m) . \Phi$ is positive because taxes are distortionary. 
The second-best problem can be formulated in a formal and compact way as follows:

$$
\max \int_{0}^{\infty} W(c, x, z, m, k, \Phi) \mathrm{e}^{-\rho t} d t
$$

subject to

$$
\begin{gathered}
\dot{k}=F[k, 1-x-T(c, m), z]-c-g, \\
U_{s}=F_{z}\left(U_{c}-U_{x} T_{c}\right) .
\end{gathered}
$$

We show that

Proposition 1 When there are restrictions on the taxation of (at least) one factor of production, the optimal inflation tax is positive, while the optimal capital income tax may be positive, negative or zero depending on whether capital and the untaxed input are complements, substitutes or independent.

Proof. The 'Ramsey optimum' requires the satisfaction of the following first-order conditions

$$
\begin{gathered}
W_{c}=\Gamma\left(1+F_{l} T_{c}\right)-\Delta A, \\
W_{x}=\Gamma F_{l}-\Delta B, \\
W_{s}=\Gamma F_{z}-\Delta D, \\
\Phi U_{x}(1-h) T_{m}=\left[\Gamma F_{l}-\Delta\left(U_{c}-U_{x} T_{c}\right) F_{z l}\right] T_{m}-\Delta U_{x} F_{z} T_{c m},
\end{gathered}
$$




$$
-\dot{\Gamma}+\Gamma \rho=\Gamma F_{k}-\Delta\left(U_{c}-U_{x} T_{c}\right) F_{z k}
$$

where

$$
\begin{gathered}
W_{c} \equiv U_{c}\left[1+\Phi\left(1+\varepsilon_{c}\right)\right], \\
W_{x} \equiv U_{x}\left[1+\Phi\left(1+\varepsilon_{x}\right)\right], \\
W_{s} \equiv U_{s}\left[1+\Phi\left(1+\varepsilon_{s}\right)\right] .
\end{gathered}
$$

$\Gamma$ and $\Delta$ represent the Lagrange multipliers on (10b) and (10c), respectively. $A, B$ and $D$ are parameter combinations. ${ }^{11} \varepsilon_{c}, \varepsilon_{x}$ and $\varepsilon_{s}$ are general equilibrium elasticities for consumption, leisure and $z$, respectively. ${ }^{12}$

If (10c) were not imposed as a constraint of the planner problem, the optimal Ramsey plan would yield the following relationship as a first-order condition for $z$

$$
\frac{U_{s}\left[1+\Phi\left(1+\varepsilon_{s}\right)\right]}{\left\{U_{c}\left[1+\Phi\left(1+\varepsilon_{c}\right)\right]-U_{x}\left[1+\Phi\left(1+\varepsilon_{x}\right)\right] T_{c}\right\}}=F_{z},
$$

which is clearly incompatible with (10c).

With the aid of (11b), the Ramsey condition for money (11d) can be written as

\footnotetext{
${ }^{11}$ These parameter combinations are given by $\left.A=U_{s c}-F_{z}\left(U_{c c}-U_{x} T_{c c}-T_{c} U_{x c}\right)+\left(U_{c}-U_{x} T_{c}\right) T_{c} F_{z l}\right] ;$

$\left.B=U_{s x}-F_{z}\left(U_{c x}-T_{c} U_{x x}\right)+\left(U_{c}-U_{x} T_{c}\right) F_{z l}\right]$; and $D=U_{s s}+\left(U_{c}-T_{c} U_{x}\right) F_{z z}-F_{z}\left(U_{c s}-\right.$ $\left.T_{c} U_{x s}\right)$.

${ }^{12}$ The expressions for these elasticities are $\varepsilon_{c}=\frac{c U_{c c}}{U_{c}}-(l+h T) \frac{U_{x c}}{U_{c}}+\frac{U_{x}}{U_{c}}(1-h) T_{c}-z \frac{U_{s c}}{U_{c}} ;$

$\varepsilon_{x}=\frac{c U_{c x}}{U_{x}}-(l+h T) \frac{U_{x x}^{c}}{U_{x}}-z \frac{U_{s x}}{U_{x}} ;$ and $\varepsilon_{s}=\frac{c U_{c s}}{U_{s}}-(l+h T) \frac{U_{x s}}{U_{s}}-z \frac{U_{s s}}{U_{s}}$.
} 


$$
\left\{U_{x}+\Phi\left(h+\varepsilon_{x}\right) U_{x}+\Delta\left[U_{s x}-F_{z}\left(U_{c x}-T_{c} U_{x x}\right)\right]\right\} T_{m}=\Delta F_{z} U_{x} T_{c m} .
$$

By plugging (6d) into this equation it yields the optimal inflation rate

$$
i^{*}=-\frac{\Delta F_{z} U_{x}^{2} T_{c m}\left(U_{c}-U_{x} T_{c}\right)^{-1}}{\left\{U_{x}+\Phi\left(h+\varepsilon_{x}\right) U_{x}+\Delta\left[U_{s x}-F_{z}\left(U_{c x}-T_{c} U_{x x}\right)\right]\right\}}>0 .
$$

As $T_{c m}<0$, and $\Delta$ and the denominator of (13a) are positive, the optimal monetary policy is the Phelps (1973) rule, thus making it necessary to set a positive inflation tax. This anti-Friedman result derives from the impossibility of taxing $z$ optimally, i.e. $\Delta>0$.

In the long-run, by substituting the 'modified golden rule', derived from (6e) -i.e., $\rho=\left(1-\tau_{k}\right) F_{k}$ - into (11e), the optimal capital income tax rate is obtained; this is given by

$$
\tau_{k}^{*}=\frac{\Delta}{\Gamma} \frac{\left(U_{c}-U_{x} T_{c}\right) F_{z k}}{F_{k}} \gtrless 0 .
$$

It is optimal to tax (subsidize) capital income if capital and the untaxed input are Edgeworth complementary (substitutable) - that is, $F_{z k}>(<) 0$. If $k$ and $z$ are independent, i.e. $F_{z k}=0$, the Chamley-Judd result (that is, $\left.\tau_{k}^{*}=0\right)$ is obtained.

The optimal labor tax rate - derived by constrasting the optimal conditions for the private and Ramsey problems regarding $c$ and $x$ - is given by

$$
\tau_{l}^{*}=\frac{\left[U_{c} U_{x} \Phi\left(\varepsilon_{x}-\varepsilon_{c}\right)+\Delta\left(U_{c} B-U_{x} A\right)\right]}{\left(U_{c}-U_{x} T_{c}\right)\left(W_{x}+\Delta B\right)} .
$$

$\tau_{l}^{*}$ is positive for plausible parameter values. ${ }^{13} \square$

\footnotetext{
${ }^{13}$ The optimal labor tax can be equivalently be expressed as

$$
\tau_{l}^{*}=\frac{\left[\left(U_{c}-U_{x} T_{c}\right)\left(W_{c}+A\right)-U_{c} \Gamma\right]}{T_{c}\left(U_{c}-U_{x} T_{c}\right)\left(W_{x}+\Delta B\right)} .
$$
}


If a factor of production cannot be taxed, the minimizaton of the excess burden of taxation requires to optimally distribute taxation over money and incomes from taxable inputs. Our discoveries would remain valid if $z$ were taxed, but not at an optimal rate.

In a context in which the tax code is not sufficiently rich, the inflation tax represents an indirect way of taxing the untaxable inputs. ${ }^{14}$ If there were no restrictions on the taxation of factor $z$, i.e. $\Delta=0$, the optimal taxes on money and capital income would be both zero.

This result extends the operative validity of the Phelps (1973) intuition to an intertemporal optimizing model of capital accumulation with factor income taxation and tax restrictions.

The economic ratio of the optimal tax configuration discovered here is imputable to the invalidity of the Diamond and Mirrlees (1971) intermediate good result when there are limitations to the optimal tax setting, as has been demonstrated by Munk (1980). The mechanical motivation of our results, instead, is based on the fact that, when additional constraints have to be imposed on the Ramsey problem, a second partial derivative of the transactions technology enters the first-order condition of the planner problem for real money balances. This is the element that mechanically undermines the optimality of the Friedman rule.

The simplest application of Proposition 1 is obtained when there are only two inputs, labor and capital, and two tax instruments, that is, inflation and capital income taxes. In this case, we get:

Proposition 1.1 In an infinite-lived monetary model with elastic laborleisure choices, Ramsey optimality prescribes positive taxation of money and capital if labor cannot be taxed.

Proof. The optimal condition for real money balances, obtained from (13a), implies a positive inflation tax. The Ramsey plan for the capital tax rate, once combined with the private efficiency condition (6e), yields (13b) with $F_{l k}$ that now replaces $F_{z k}$; thus, $\tau_{k}^{*}>0$ as $F_{l k}>0$, as the production function is linearly homogeneous in $k$ and $l$.

\footnotetext{
${ }^{14}$ Our discovery is very similar to what is found by Nicolini (1998) in a model with tax evasion. In the Nicolini (1998) analysis, the inflation tax serves as a tool to tax the underground sector, as 'shadow' transactions are regulated through cash.
} 


\section{Monopolistic competition and taxation of profits}

\subsection{The model}

Consider an immortal monetary economy in which there are product market imperfections. The role of monopolistic competition for the validity of the Friedman rule has been investigated by Schmitt-Grohè and Uribe (2004a), whose analysis is extended here to include endogenous capital formation, as well as capital and profit income taxation.

The consideration of firms with market power is based on the supplyside of the Benhabib and Farmer (1994) analysis. There are two sectors in the economy: a final good sector, which is perfectly competitive, and an intermediate good sector, which is monopolistically competitive. The perfectly competitive sector produces a unique final good by using differentiated intermediate goods. The imperfectly competitive sector, instead, produces intermediate goods by using physical capital and labor. ${ }^{15}$

The final good $y$ is produced by using the following linearly homogeneous production function

$$
y=\left(\int_{0}^{1} y_{i}^{1-\mu} d i\right)^{\frac{1}{1-\mu}}
$$

where $y_{i}$ represents the $i$ th intermediate good, and $i$ is continuous in the interval $[0,1] ; \mu \epsilon[0,1)$ is the reciprocal of the elasticity of substitution among intermediate inputs. Final good producing firms maximize profits by choosing the optimal quantity of each intermediate good. The first-order condition for profit maximization yields the following input demand

$$
\frac{p_{i}}{p}=\left(\frac{y_{i}}{y}\right)^{-\mu},
$$

\footnotetext{
${ }^{15}$ Shaw, Chang and Lai (2006) use a similar production structure for the analysis of the optimal inflation tax. Their analysis, however, differs greatly from ours since they consider an endogenous growth model with production externalities, a cash-in-advance constraint and a non-proper Ramsey analysis in which lump-sum transfers adjust endogenously.
} 
where $p_{i}$ is the price of the $i$ th intermediate good and $p$ the price of the final good. Since the final sector is perfectly competitive, firms' profits should be

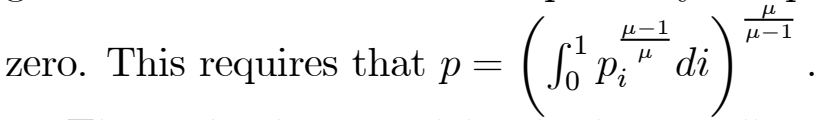

The technology used in the intermediate goods sector is, instead, described by

$$
y_{i}=F\left(k_{i}, l_{i}\right)
$$

where $k_{i}$ and $l_{i}$ represent capital and labor used for producing intermediate good $i$ th, respectively. $F(\cdot)$ satisfies the neoclassical properties of regularity and is constant returns to scale.

If we use (15), the $i$ th firm's profit in the intermediate sector (measured in terms of the final good) can be expressed as $\Pi_{i}=y^{\mu} y_{i}^{1-\mu}-w l_{i}-r k_{i}$, where $r$ is the real rental on capital and $w$ the real wage. The $i$ th intermediate good producer maximizes $\Pi_{i}$ by taking into account the production function (16). The first-order conditions for his/her problem are

$$
\begin{aligned}
& (1-\mu) y^{\mu} y_{i}^{-\mu} F_{k_{i}}\left(k_{i}, l_{i}\right)=r, \\
& (1-\mu) y^{\mu} y_{i}^{-\mu} F_{l_{i}}\left(k_{i}, l_{i}\right)=w .
\end{aligned}
$$

We consider a situation of symmetric equilibrium in which $k_{i}=k, l_{i}=l$, $p_{i}=p$ and $y_{i}=y$. In this situation, the real rental on capital and the real wage are given by

$$
\begin{aligned}
& (1-\mu) F_{k}(k, l)=r, \\
& (1-\mu) F_{l}(k, l)=w .
\end{aligned}
$$


Profits in the intermediate good sector profits are positive and equal to $\Pi=\mu F(k, l) . \quad \mu$ measures the degree of product market imperfections; if the market power of firms is zero (that is, $\mu=0$ ), the competitive case will obviously be obtained.

The utility function of consumers, defined over the infinite time span, is

$$
\int_{0}^{\infty} U(c, x) e^{-\rho t} d t
$$

where $U(\cdot)$ satisfies the usual properties of regularity.

The transaction costs technology and the time allocation constraint are given by (3) and (4), respectively. The consumers' intertemporal budget constraint is

$$
\int_{0}^{\infty}\left[c+i m-\left(1-\tau_{l}\right) w l-\left(1-\alpha \tau_{k}\right) \Pi\right] \mathrm{e}^{-\int_{0}^{t}\left(1-\tau_{k}\right) r d u} d t=k_{0}
$$

where $\alpha$ is a parameter taking alternatively value 0 or 1 , and the value of government bonds and real money balances at time 0 have been set equal to zero.

Dividends $\Pi$ enter (19) as consumers are the owners of firms. As profits exert only income effects, ${ }^{16}$ their separate optimal taxation would prescribe a confiscatory $100 \%$ rate. Since such an optimal taxation of profits is not feasible in practice, ${ }^{17}$ we consider two alternative regimes of profit taxation: one in which profits are untaxed, and one in which they are taxed at the same rate as capital income. ${ }^{18}$ These two polar regimes can be captured through the dummy $\alpha$. If $\alpha=0$, profits are tax free and only the capital income tax

\footnotetext{
${ }^{16}$ This is because profits do not affect the marginal choices of consumers, but they only enter their disposable income.

${ }^{17}$ Such an impracticability could be due to many reasons, like, for example, tax authorities that may be unable to distinguish capital income from profit income, agents that may conceal profits to the fiscal authority, fiscal policy-makers that may not have the political strength or the political mandate from their voters to implement such a type of taxation.

${ }^{18}$ Guo and Lansing (1999) consider identical hypotheses for the analysis of the optimal capital income tax rate.
} 
rate is chosen optimally; if, instead, $\alpha=1$, there is a common tax rate for capital income and profits, which is set optimally. ${ }^{19}$

Consumers maximize (18) subject to (3), (4), and (19). The first-order conditions for the consumer problem are given by (6), with the exception of (6c), which now does not apply.

The feasibility constraint is given by $(7)$, when $y=F(k, l)$ is used.

\subsection{Second-best problem and the Ramsey plan}

The Ramsey problem has to be devised in such a way as to realize the possibility that capital income and profits are taxed at the same rate.

By employing $\left(1-\tau_{l}\right) w=\frac{U_{x} \mathrm{e}^{-\rho t}}{\lambda \mathrm{e}^{-\int_{0}^{t}\left(1-\tau_{k}\right) r d u}}=\frac{U_{x}}{\xi}$-where $\xi=\left(U_{c}-U_{x} T_{c}\right)-$ and $\lambda=U_{c}[0]$, the implementability constraint can be expressed as

$$
\int_{0}^{\infty}\left\{c U_{c}-U_{x}[1-x-(1-h) T]-\left(1-\alpha \tau_{k}\right) \Pi \xi\right\} \mathrm{e}^{-\rho t} d t=\lambda k_{0} .
$$

The efficient second-best tax structure is found by maximizing the utility functional (18) subject to the implementability constraint (20), the feasibility constraint (7) with $F(k, l)$ and the Euler equation (6e), once the transaction technology (3), the time allocation constraint (4) and the firms' demand for capital (17a') are taken into account. The additional constraint (6e) is considered as $\tau_{k}$ enters the implementability constraint when profits are subject to taxation (that is, $\alpha \neq 0$ ). Equation (6e) can be written as $\dot{\xi}=$ $\xi\left[\rho-\left(1-\tau_{k}\right) r\right]$, since, by using $(6 \mathrm{a})$ and $(6 \mathrm{~b})$, it can be easily shown that $\frac{U_{c}}{\left[1+\left(1-\tau_{l}\right) w T_{c}\right]}=\left(U_{c}-U_{x} T_{c}\right) \equiv \xi$

Now the Ramsey problem can be expressed as

$$
\max \int_{0}^{\infty} W\left(c, x, m, k, \tau_{k}, \Phi\right) \mathrm{e}^{-\rho t} d t
$$

subject to

\footnotetext{
${ }^{19}$ Note that the confiscatory taxation of profits can be obtained when $\alpha=\frac{1}{\tau_{k}}$.
} 


$$
\begin{gathered}
\dot{k}=F(k, 1-x-T)-c-g, \\
\dot{\xi}=\xi\left[\rho-\left(1-\tau_{k}\right)(1-\mu) F_{k}\right], \\
\xi=\left(U_{c}-U_{x} T_{c}\right),
\end{gathered}
$$

where

$W\left(c, x, m, k, \tau_{k}, \Phi\right)=U(c, x)+\Phi\left\{c U_{c}-U_{x}[1-x-(1-h) T]-\left(1-\alpha \tau_{k}\right) \Pi \xi\right\}$

$\Phi>0$ is the Lagrange multiplier associated with $(20), \Pi=\mu F(k, l)$, and $T=T(c, m)$.

How is the optimal tax structure characterized?

Our findings can be synthesized as follows

Proposition 2 In a monopolistically competitive monetary model of capital formation, in which the confiscatory taxation of profits is not praticable, the efficient tax structure requires to tax labor and money, and to subsidize capital if profits cannot be taxed. If capital income and profits are taxed equally, optimality calls for positive capital and labor tax rates and a zero inflation tax.

Proof. The first-order conditions for the Ramsey problem are

$$
\begin{gathered}
W_{c}=\Gamma\left(1+F_{l} T_{c}\right)-\Omega \xi\left(1-\tau_{k}\right)(1-\mu) F_{k l} T_{c}+\Delta\left(U_{c c}-U_{x} T_{c c}-T_{c} U_{x c}\right) \\
W_{x}=\Gamma F_{l}-\Omega \xi\left(1-\tau_{k}\right)(1-\mu) F_{k l}+\Delta\left(U_{c x}-T_{c} U_{x x}\right)
\end{gathered}
$$




$$
\begin{gathered}
W_{m}=\left[\Gamma F_{l}-\Omega \xi\left(1-\tau_{k}\right)(1-\mu) F_{k l}\right] T_{m}-\Delta U_{x} T_{c m}, \\
-\dot{\Gamma}+\Gamma \rho=-\Phi \xi\left(1-\alpha \tau_{k}\right) \Pi_{k}+\Gamma F_{k}-\Omega \xi\left(1-\tau_{k}\right)(1-\mu) F_{k k}, \\
-\dot{\Omega}+\rho \Omega=-\Phi\left(1-\alpha \tau_{k}\right) \Pi+\Omega\left[\rho-\left(1-\tau_{k}\right)(1-\mu) F_{k}\right]+\Delta, \\
\Omega=-\frac{\alpha \Phi \Pi}{(1-\mu) F_{k}},
\end{gathered}
$$

where

$$
\begin{gathered}
W_{c} \equiv U_{c}\left[1+\Phi\left(1+\eta_{c}\right)\right]+\Phi \xi\left(1-\alpha \tau_{k}\right) \Pi_{l} T_{c}, \\
W_{x} \equiv U_{x}\left[1+\Phi\left(1+\eta_{x}\right)\right]+\Phi \xi\left(1-\alpha \tau_{k}\right) \Pi_{l}, \\
W_{m} \equiv \Phi\left[U_{x}(1-h)+\xi\left(1-\alpha \tau_{k}\right) \Pi_{l}\right] T_{m},
\end{gathered}
$$

where $\Pi_{j}=\mu F_{j}$ for $j=k, l . \Gamma, \Omega$, and $\Delta$ are Lagrange multipliers on (21b), (21c) and (21d), respectively; $\eta_{c}$ and $\eta_{x}$ represent general equilibrium elasticities for consumption and leisure, respectively. ${ }^{20}$

In the steady state equilibrium, it can be easily obtained, by combining (22e) and (22f), that $\Delta=(1-\alpha) \Phi \mu F$.

The optimal condition for real money balances (22c) can be expressed -after using (22b), (23), and the previous expression for $\Delta$ - as

\footnotetext{
${ }^{20}$ These elasticities are defined as
$\eta_{c}=\frac{c U_{c c}}{U_{c}}-(l+h T) \frac{U_{x c}}{U_{c}}+\frac{U_{x}}{U_{c}}(1-h) T_{c} ;$ and $\eta_{x}=\frac{c U_{c x}}{U_{x}}-(l+h T) \frac{U_{x x}}{U_{x}}$.
} 


$$
\left\{U_{x}\left[1+\Phi\left(\eta_{x}+h\right)\right]-(1-\alpha) \Pi \Phi\left(U_{c x}-T_{c} U_{x x}\right)\right\} T_{m}=(1-\alpha) \Phi \Pi U_{x} T_{c m} .
$$

By using (6c), the optimal inflation rate is

$$
i^{*}=-\frac{(1-\alpha) \Phi \Pi U_{x}^{2} T_{c m}\left(U_{c}-U_{x} T_{c}\right)^{-1}}{\left\{U_{x}\left[1+\Phi\left(\eta_{x}+h\right)\right]-(1-\alpha) \Pi \Phi\left(U_{c x}-T_{c} U_{x x}\right)\right\}}>0 .
$$

Second-best optimality requires that $i^{*}>0$ if $\alpha=0$. Therefore, when profits are taxed less than capital income $(\alpha<1)$, the optimal monetary policy satisfies the Phelps (1973) rule. If, instead, capital income and profits are taxed at the same rate (i.e., $\alpha=1$ ), the Friedman rule is optimal.

The joint use of (17a') and (6e) implies that, in the steady state, (1 $\left.\tau_{k}\right)(1-\mu) F_{k}=\rho$. Employing this equation together with $(22 \mathrm{~d})$ and $(22 \mathrm{f})$ yields the following optimal capital income tax rate

$$
\tau_{k}^{*}=-\frac{\mu\left[\Gamma-\Phi \xi\left(1-\alpha \frac{F F_{k k}}{F_{k}^{2}}\right)\right]}{\left[\Gamma(1-\mu)+\alpha \Phi \mu \xi\left(1-\frac{F F_{k k}}{F_{k}^{2}}\right)\right]} .
$$

The sign of the optimal capital income tax is ambiguous. ${ }^{21}$ If $\alpha=0, \tau_{k}^{*}<0$ as $\Gamma-\Phi \xi=\xi+\Phi\left(U_{c} \eta_{c}-U_{x} \eta_{x} T_{c}\right)>0$. In this case, capital taxation alleviates the distortionary role of market imperfections as suggested by Judd (2002). If instead $\alpha=1, \tau_{k}^{*}>0$ since the profit tax rate, constrained to be equal to the capital income tax rate, exerts only income effects.

The efficient labor income tax rate - derived by combining (6a), (6b), (22a) and (22b) - is given by

$$
\tau_{l}^{*}=\frac{\left(W_{x}-\tilde{B}\right)\left[(1-\mu) U_{c}+\mu U_{x} T_{c}\right]+(1-\mu)\left(\frac{U_{c}}{T_{c}}-U_{x}\right) \tilde{E}-U_{x}\left(W_{c}-\tilde{A}\right)}{\left[(1-\mu)\left(U_{c}-U_{x} T_{c}\right)\left(W_{x}-\tilde{B}+\tilde{E} / T_{c}\right)\right]} 0
$$

\footnotetext{
${ }^{21}$ Also Guo and Lansing (1999) show that when a common tax rate on capital income and profits is considered in a real intertemporal optimizing model with imperfect competition, the optimal tax rate on capital income can be either positive or negative.
} 
where $\widetilde{A}, \widetilde{B}$ and $\widetilde{E}$ are combinations of parameters. ${ }^{22}$ The existence of positive profits, that can be either taxed or untaxed, has no substantial implications for the optimal labor tax rate, which is plausibly positive.

These results are to be ascribed to the good market imperfections, which imply that positive profits appear in the intertemporal budget constraint of consumers. Since $\Pi$ and $T_{c}$ are elements of the pseudo-welfare function of the social planner -by means of the implementability constraint $(20)-T_{c m}<0$ enters directly the first-order condition of the Ramsey problem for $m$, thus invalidating the Friedman "full liquidity" rule. ${ }^{23}$

These findings generalize and extend the result of Schmitt-Grohè and Uribe (2004a) by showing that the zero inflation tax may be optimal also when profit taxation is non-confiscatory. Here, what is new (in addition to the endogeneity of capital and the use of capital taxation), and to some extent surprising, is that the Friedman rule is valid if capital and profits are taxed at the same rate $(\alpha=1)$. In order to be satisfied, the "full liquidity rule" needs a flexible choice of the tax instrument on profits and capital.

Notice that the violation of the Friedman rule is satisfied when both the hypotheses $\alpha<1$ and $\Pi>0$ (i.e., $\mu>0$ ) hold. In this case, the inflation tax constitutes an indirect way of taxing profits. The optimal taxation of profits at the same rate as capital income (i.e., $\alpha=1$ ) or at a confiscatory rate (i.e., $\alpha=\frac{1}{\tau_{k}}$ ) results in the validity of the zero inflation tax result; the same result is true when profits (i.e., $\mu=0$ ) are absent. If instead $\mu=0$ and hence $\Pi=0$, the burden of taxation is born by labor taxation alone, since $i^{*}=0$ and $\tau_{k}^{*}=0$.

Once again, the analysis conducted in this section demonstrates that the crucial factor for the invalidity of the Friedman rule is the existence of restrictions on the set of fiscal instruments that can be optimally used. Now the Diamond and Mirrlees (1971) principle has become invalid because of positive profits as shown by Stiglitz and Dasgupta (1971).

\footnotetext{
${ }^{22}$ They are given by the expressions: $\tilde{A}=\Delta\left(U_{c c}-U_{x} T_{c c}-T_{c} U_{x c}\right) ; \widetilde{B}=\Delta\left(U_{c x}-T_{c} U_{x x}\right)$; and $\widetilde{E}=\Omega \xi\left(1-\tau_{k}\right)(1-\mu) F_{k l} T_{c}$.

${ }^{23}$ This observation has some parallelism with the methodological remarks on the zero capital tax rule put forward by Jones, Manuelli and Rossi (1997, p. 105-06).
} 
With regard to the mechanics of the results, we can observe that the existence of monopolistic profits that are not optimally taxed or not taxed at the same rate as capital implies a change in the way in which the transaction costs technology and its derivatives (i.e., the ultimate cause of the Friedman rule validity) enter the implementability constraint.

\section{Perfect competition and taxation of prof- its/rents}

In this section, we show that the Friedman rule is invalid if decreasing returns to scale in the reproducible inputs are considered in monetary models with perfect competition and a homogeneous transactions technology.

\subsection{An economy with productive public goods}

Consider a perfectly competitive monetary economy in which the government spends for a productive public good, $g$, that cannot be sold to firms. Productive public spending, which is exogenosuly given, is financed through distortionary taxes on money and factor incomes. Suppose -as in Jones, Manuelli and Rossi (1993) - that the production function -that is, $y=F(k, l, g)$ - is linearly homogeneous in capital, labor and $g$. The presence of the productive public good implies that there are positive profits, given by $\Pi=g F_{g}{ }^{24}$

Profits enter the intertemporal budget constraint of consumers. Let us suppose that profits are either untaxed or taxed at the same rate as capital income. Therefore, the consumer intertemporal budget constraint is still given by $(19)$, when $\Pi=g F_{g}$.

The optimal tax structure is described by

Proposition 3 In an immortal monetary model of capital accumulation with productive government spending -that cannot be sold to firms-and decreasing

\footnotetext{
${ }^{24}$ In the technological hypotheses considered here, the optimal capital tax rate differs from zero as shown by Jones, Manuelli and Rossi (1993). If $F(k, l, g)$ were homogeneous of degree one in $k$ and $l$ alone, profits as well as the optimal tax rate on capital income would be zero; see Judd (1999).
} 
returns to scale with respect to the reproducible inputs, second-best efficiency prescribes positive taxation of money and labor. Capital can be taxed or subsidized or left tax free depending on whether capital and productive public spending are complementary or substitutable or independent.

Proof. The Ramsey problem is given by (21) with $\mu=0$ in (21c) and $\Pi=g F_{g}$ in the pesudo-welfare function of the social planner. Therefore, (22) and (23) characterize the Ramsey plan if $\mu=0, \Pi=g F_{g}$ and $\Pi_{j}=g F_{g j}$ for $j=k, l$.

The optimal inflation tax is still given by (24a). ${ }^{25}$ Thus, once again, the Friedman rule is nonoptimal if profits and income from capital are taxed differently $(\alpha=0)$. Otherwise, an equal tax treatment of capital and profits $(\alpha=1)$ results in the optimality of a zero inflation tax.

In the steady state, the optimal capital income tax rate is given by

$$
\tau_{k}^{*}=-\frac{g \Phi\left(U_{c}-U_{x} T_{c}\right)\left(F_{k} F_{k g}-\alpha F_{g} F_{k k}\right)}{\left[\Gamma F_{k}^{2}+\alpha g \Phi\left(U_{c}-U_{x} T_{c}\right)\left(F_{k} F_{k g}-\alpha F_{g} F_{k k}\right)\right]} .
$$

If $\alpha=0$, capital income should be taxed or subsidized in the long-run depending on whether capital and productive public spending are Edgeworth complements or substitutes, i.e. $F_{g k}>0$ or $F_{g k}<0$; the optimal capital income is zero if $k$ and $g$ are strongly separable. If $\alpha=1, \tau_{k}^{*}$ depends on the sign of the expression $F_{k} F_{k g}-F_{g} F_{k k}$, which can be either positive (more likely) or negative (less likely).

Also this theoretical case confirms that the existence of positive profits that are untaxed is at the base of the violation of the Friedman rule.

\subsection{An economy with a fixed input/asset}

Consider a perfectly competitive monetary economy with an exogenously given input, like, for example, land.

\footnotetext{
${ }^{25}$ Note that when profits are tax free (i.e., $\alpha=0$ ), the first-order conditions of the planner problem are equivalent to those seen in Section 2 if the term $z U_{s}$ in (9) is replaced by $\left(U_{c}-U_{x} T_{c}\right) g F_{g}(k, l, g)$.
} 
The production function is given by the constant returns to scale technology $y=F(k, l, z)$. The demand for land formulated by firms is given by $F_{z}(k, l, z)=v$, where $v$ is the real land reward. Land is inelastically supplied and fully used in production. Therefore, its total amount can be normalized to one.

Land is at the same time a factor of production and an asset. If we denote the price of land in real terms by $q, q z$ will indicate the value of land, i.e. the amount of nonhuman wealth devoted to land. Assuming that assets are perfectly substitutable, the following condition must hold under perfect foresight

$$
r=\frac{v}{q}+\frac{\dot{q}}{q}
$$

If this condition is substituted in the consumers' flow budget constraint, an intertemporal budget constraint equivalent to (19) is obtained, after integrating forward and imposing no Ponzi games. Profits are now replaced by land rents, i.e. $\Pi=v(k, l)=F_{z}(k, l)$. Two regimes for taxing pure rents are contemplated: tax exemption of rents and taxation of rents at the same rate as capital income.

We have that

Proposition 4 In a monetary economy with an inelastically supplied input, the impossibility to tax pure rents implies the optimality of a positive inflation tax. If rents are taxed at the same rate as capital income, the optimal inflation tax is zero. Capital taxation is governed by the Edgeworth complementarity/substitutability relationships between capital and the fixed factor.

Proof. The Ramsey plan is described by (22) and (23) if $\mu=0, \Pi=v=F_{z}$ and $\Pi_{j}=v_{j}=F_{z j}$ for $j=k, l$. The optimal inflation and capital income taxes are obtained from $(24 \mathrm{a})$ and $(25)$, once $\Pi$ and $F_{z k}$ are replaced by $v$ and $v_{k}$, respectively. ${ }^{26}$

\footnotetext{
${ }^{26}$ When rents are not taxed, the normative analysis of this case can be obtained from Section 2 if $z U_{s}$ in the implementability constraint (9) is replaced by $v(k, l)=F_{z}$.
} 
When pure rents are not taxed, the optimality of a positive inflation tax emerges. If pure rents and capital income are taxed equally, then the Friedman rule is optimal.

If capital is an Edgeworth complement (substitute) of land, the long-run capital income tax is positive (negative).

\section{A perfectly competitive economy with ex- ogenous government transfers}

Consider a perfectly competitive monetary economy with infinitely lived agents and two inputs, labor and capital. Assume that the government distributes lump-sum transfers - denoted by $\tilde{n}$ once expressed in terms of the numeraire - to consumers; these transfers are exogenously given. As these transfers are not fixed once specified in terms of consumption, the relative prices (and in particular the nominal interest rate) affect household disposable income through an additional channel that has not been considered before.

The intertemporal budget constraint of consumers in this two-factor economy is given by (5) if $\tilde{n}$ replaces $v z$, while the implementability constraint is given by $(9)$ if $\left(U_{c}-U_{x} T_{c}\right) \tilde{n}$ replaces $z U_{s}$.

In this case, we have the following normative results

Proposition 5 When exogenous government transfers are considered in a standard monetary model with a homogeneous transactions technology, the optimal taxes on money and labor are positive, while the optimal capital income tax is zero.

Proof. It can be easily shown that the Ramsey allocation satifies the following condition for real money balances

$$
\Phi\left[U_{x}(1-h) T_{m}+\tilde{n} U_{x} T_{c m}\right]=\Gamma F_{l} T_{m} .
$$

After some algebraic manipulations (carried out with the aid of the social optimal condition on $x$ ), this equation becomes 


$$
i^{*}=-\frac{\tilde{n} \Phi U_{x} T_{c m}}{\left(U_{c}-U_{x} T_{c}\right)\left[1+\Phi\left(\eta_{x}+h\right)\right]}>0 .
$$

Thus, the optimal inflation tax is different from zero if the value of government transfers is non-zero. ${ }^{27}$

The Ramsey plan also contemplates a zero capital income tax - as the capital stock does not enter the pseudo-welfare function and there are no additional constraints - and a positive labor income tax. $\square$

\section{Concluding remarks}

Since the study of Phelps (1973) the question of the optimal inflation tax has been investigated by applying Ramsey's second-best analysis. Phelps (1973) demonstrates the optimality of collecting revenues from seignorage, thus invalidating the Friedman (1969) zero inflation tax rule.

By applying the Ramsey approach to dynamic settings, some recent papers have instead demonstrated, although with some dissonance, the optimality of the Friedman rule in infinite-lived models with distortionary taxes. Among the dissonant contributions, Mulligan and Sala-i-Martin (1997) emphasize that the validity of the Friedman rule is a matter of functional forms for tastes and the shopping-time technology, while Schmitt-Grohè and Uribe (2004a) argue that, when there are product market imperfections, such a rule is satisfied if and only if monopoly profits are taxed at a confiscatory rate.

In the optimal inflation tax literature developed so far, the consideration of an endogenous capital stock has been quite infrequent, while that of capital income taxation is totally absent. In this article, on the contrary,

\footnotetext{
${ }^{27}$ Note that, with a transactions technology that is homogeneous of any degree in money balances and consumption, the hypothesis of exogenous government transfers can be functionally assimilated to the case of a non-zero marginal cost of producing money -a way of undermining the Friedman rule in such a setup, as emphasized by Correia and Teles $(1996,1999)$ and De Fiore and Teles (2003). This is because the hypothesis of government transfers (like the assumption of the positive marginal cost of producing money) makes de facto the transaction technology non-homogeneous. See Mulligan and Sala-i-Martin (1997).
} 
we have adopted a broader perspective by considering capital formation as well as capital and labor income taxation to explore the proposition that the optimal inflation tax is zero. In order to eliminate any ambiguity in the interpretation of the results, a monetary setup in which the optimality of a zero nominal interest rate is satisfied (when the usual assumptions of literature are considered) has been employed.

We have discovered the existence of a connection between the Friedman rule and the Chamley-Judd result on the optimality of zero capital income tax as money and capital taxation have similar theoretical justifications. In intertemporal optimizing models of capital formation with infinite horizons, money that facilitates transactions and distortionary factor income taxes, we have found that the Friedman rule is in general nonoptimal when the second-best capital tax rate is non-zero.

The paper has demonstrated the optimality of a positive inflation tax when there are limitations on taxation. These are tax restrictions on productive factors, profits in an economy with product market imperfections, and profits/rents in an economy with perfect competition and decreasing returns to scale in the reproducible inputs. ${ }^{28}$ With restrictions on taxation of production factors or profits/rents, the inflation tax represents an indirect way to tax what cannot be taxed. The nonoptimality of the Friedman rule derives from the invalidity of the Diamond and Mirrlees (1971) principle on the prohibition against intermediate goods taxation.

Moreover, we have shown that exogenous transfers distributed by the government to consumers imply a positive inflation tax; in such a case, the capital income tax is instead zero. ${ }^{29}$

From a mechanical standpoint, we have discovered that the optimality of the Friedman rule in models with shopping-time costs fails when: i) partial derivatives of the transaction costs technology enter the implementability constraint and hence the planner pseudo-welfare function; ii) there are additional constraints faced by the social planner, that private agents do not

\footnotetext{
${ }^{28}$ Monopoly profits can be assimilated to rents since they represent incomes from monopoly rights, some sort of non-reproducible factors.

${ }^{29}$ Note that constant government transfers ensure that the optimal human-capital income tax is non-zero in real models of physical and human capital formation. See Jones, Manuelli and Rossi $(1993,1997)$.
} 
face, involving partial derivatives of the transactions technology. ${ }^{30}$

Finally, another case, that has not been considered in this paper, in which the joint invalidity of the Friedman and Chamley-Judd rules may occur, is obtained when there are wealth effects in the optimal consumer choices. ${ }^{31}$ As in such a case money and capital appear directly in the maximand function of the 'Ramsey problem' through the stock of wealth, the optimal prescriptions on the zero money and capital income taxation are jointly invalid.

\footnotetext{
${ }^{30}$ These conditions are parallel to those established by Jones, Manuelli and Rossi (1997, pp. 105-6) for the optimality of the zero capital income tax.

${ }^{31}$ This case can be obtained, for example, when elastic fertility choices (i.e., endogenous population growth) are introduced in a neoclassical monetary growth model. Nonhuman wealth affects fertility choices as the consumer optimum requires that the marginal rate of substitution of fertility for consumption must equal the opportunity cost of one unit of fertility; this opportunity cost is given by the marginal product of labor (in terms of fertility) plus per capita wealth. See, for example, Palivos (1995).
} 


\section{References}

Abel, A.B. (1987), "Optimal Monetary Growth", Journal of Monetary Economics, 19, 37-50.

Atkinson, A.B. and J.E. Stiglitz, (1972), "The Structure of Indirect Taxation and Economic Efficiency", Journal of Public Economics, 1, 97-119.

Bailey, M.J. (1956), "The Welfare Cost of Inflationary Finance", Journal of Political Economy, 64, 93-110.

Benhabib, J. and R.E.A. Farmer, (1994), "Indeterminacy and Increasing Returns", Journal of Economic Theory, 63, 19-41.

Bhattacharya, J., Haslag, J.H. and A. Martin, (2005), "Heterogeneity, Redistribution, and the Friedman Rule", International Economic Review, 46, 437-54.

Chamley, C. (1985), "On a Simple Rule for the Optimal Inflation Rate in Second Best Taxation", Journal of Public Economics, 26, 35-50.

Chamley, C. (1986), "Optimal Taxation of Capital Income in General Equilibrium with Infinite Lives", Econometrica, 54, 607-22.

Chari, V.V., Christiano, L.J., and P.J. Kehoe, (1996), "Optimality of the Friedman Rule in Economies with Distorting Taxes", Journal of Monetary Economics, 37, 203-23.

Chari, V.V., and P.J. Kehoe, (1999), "Optimal Fiscal and Monetary Policy", in Taylor, J.B. and M. Woodford (eds), Handbook of Macroeconomics, Elsevier Science, Amsterdam, Volume 1C, 1671-1745.

Correia, I.H. (1996), "Should Capital Income Be Taxed in the Steady State?", Journal of Public Economics, 60, 147-51.

Correia, I.H., Nicolini, J.P. and P. Teles, (2008) "Optimal Fiscal and Monetary Policy: Equivalence Results", Journal of Political Economy, 116, 141-70.

Correia, I.H. and P. Teles, (1996), "Is the Friedman Rule Optimal when Money is an Intermediate Good?", Journal of Monetary Economics, 38, 22344.

Correia, I.H. and P. Teles, (1999), " The Optimal Inflation Tax", Review of Economic Dynamics, 2, 325-46. 
De Fiore, F. and P. Teles, (2003), "The Optimal Mix of Taxes on Money, Consumption and Income", Journal of Monetary Economics, 50, 871-87.

Diamond, P.A. and J.A. Mirrlees, (1971), "Optimal Taxation and Public Production: I-Production Efficiency", and "Optimal Taxation and Public Production II: Tax Rules", American Economic Review, 61, 8-27 and 26178.

Faig, M. (1988), "Characterization of the Optimal Tax on Money When It Functions as a Medium of Exchange", Journal of Monetary Economics, $22,137-48$.

Friedman, M. (1969), "The Optimum Quantity of Money", in M. Friedman (ed.) The Optimum Quantity of Money and Other Essays, Chicago: Aldine, 1-50.

Gahvari, F. (1988), "Lump-Sum Taxation and the Superneutrality and Optimum Quantity of Money in Life Cycle Growth Models", Journal of Public Economics, 36, 339-67.

Guidotti, P. and C.A. Vegh, (1993), "The Optimal Inflation Tax When Money Reduces Transactions Costs: A Reconsideration", Journal of Monetary Economics, 31, 189-205.

Guo, J.T. and K.J. Lansing, (1999), "Optimal Taxation of Capital Income with Imperfectly Competitive Product Markets", Journal of Economic Dynamics and Control, 23, 967-95.

Jones, L.E., Manuelli R.E., and P.E. Rossi, (1993), "On the Optimal Taxation of Capital Income", NBER working paper no. 4525.

Jones, L.E., Manuelli R.E., and P.E. Rossi, (1997), "On the Optimal Taxation of Capital Income", Journal of Economic Theory, 73, 93-117.

Judd, K.L. (1985), "Redistributive Taxation in a Simple Perfect Foresight Model", Journal of Public Economics, 28, 59-83.

Judd, K.L. (1999), "Optimal Taxation and Spending in General Equilibrium Competitive Growth Models", Journal of Public Economics, 71, 1-26.

Judd, K.L. (2002), "Capital-Income Taxation with Imperfect Competition", American Economic Review, 92, 417-21.

Kimbrough, K.P., (1986), "The Optimum Quantity of Money Rule in the Theory of Public Finance", Journal of Monetary Economics, 18, 277-84.

Kocherlakota, N.R. (2005), "Optimal Monetary Policy: What We Know 
and What We Don't Know", Federal Reserve Bank of Minneapolis Quarterly Review, 29, 10-19.

Lagos, R. and R. Wright (2005), "A Unified Framework for Monetary Theory and Policy Analysis", Journal of Political Economy, 113, 463-84.

Lucas, R.E. (1990), "Supply-Side Economics: An Analytical Review", Oxford Economic Papers, 42, 293-316.

Lucas, R.E., and N.L. Stokey, (1983), "Optimal Fiscal and Monetary Policy in an Economy without Capital", Journal of Monetary Economics, $12,55-93$.

Mulligan, C.B. and X. Sala-i-Martin, (1997), "The Optimum Quantity of Money: Theory and Evidence", Journal of Money, Credit, and Banking, 29, 687-715.

Munk, K.J. (1980), "Optimal Taxation with Some Non-Taxable Commodities", Review of Economic Studies, 47, 755-65.

Nicolini, J.P. (1998), "Tax Evasion and the Optimal Inflation Tax", Journal of Development Economics, 55, 215-32.

Palivos, T., (1995), "Endogenous Fertility, Multiple Growth Paths, and Economic Convergence", Journal of Economic Dynamics and Control, 19, 1489-1510.

Phelps, E.S. (1973), "Inflation in the Theory of Public Finance", Swedish Journal of Economics, 75, 67-82.

Ramsey, F.P. (1927), "A Contribution to the Theory of Taxation", Economic Journal, 37, 47-61.

Samuelson, P.A. (1968), "What Classical and Neoclassical Monetary Theory Really Was", Canadian Journal of Economics, 1, 1-15.

Schmitt-Grohè, S. and M. Uribe, (2004a), "Optimal Fiscal and Monetary Policy under Imperfect Competition", Journal of Macroeconomics, 26, 183209.

Schmitt-Grohè, S. and M. Uribe, (2004b), "Optimal Fiscal and Monetary Policy under Sticky Prices", Journal of Economic Theory, 114, 198-230.

Shaw, M.F., Chang, J.J. and C.C. Lai, (2006), "(Non)optimality of the Friedman Rule and Optimal Taxation in a Growing Economy with Imperfect Competition", Economics Letters, 90, 412-20.

Stiglitz, J.E. and P. Dasgupta, (1971), "Differential Taxation, Public 
Goods and Economic Efficiency", Review of Economic Studies, 38, 151-74.

Woodford, M. (1990), "The Optimum Quantity of Money", Friedman Benjamin and Frank H. Hahn (eds.), Handbook of Monetary Economics, Amsterdam: North-Holland, vol. II, 1067-1152. 